\title{
A Política Externa do Brasil e a questão nuclear iraniana: vão-se os anéis, ficam os dedos.
}

The Foreign Policy of Brazil and the Iranian nuclear issue: Better lose the saddle than the horse.

Thaíse Kemer ${ }^{1}$

\section{RESUMO}

O objetivo do artigo é comparar a posição da política externa brasileira em dois momentos, a saber, no contexto da Declaração de Teerã de 2010, por ocasião da mediação do Brasil e da Turquia no contexto da Questão Nuclear Iraniana, e da Declaração de Genebra, de Novembro de 2013, elaborada pelos P5+1. Os princípios de política externa do Brasil justificaram a atuação do Brasil em 2010 e o apoio dado ao acordo de 2013.

Palavras-chave: Política Externa Brasileira; Declaração de Teerã; Questão nuclear Iraniana.

\begin{abstract}
The aim of the paper is to compare the position of Brazilian foreign policy on two occasions, namely in the context of the Tehran Declaration , 2010, during the mediation of Brazil and Turkey in the context of Iranian Nuclear Issue and the Geneva Declaration of November 2013, prepared by the P5 +1 . The principles of the Brazilian foreign policy have justified the role of Brazil in 2010 and the support given to the 2013 agreement.
\end{abstract}

Key-words: Brazilian Foreign Policy; Tehran Declaration; Iranian Nuclear Issue.

\section{Introdução}

Lançar um olhar sobre a realidade das interações entre países pode fornecer importante base empírica para a compreensão da operacionalização dos princípios que regem a política externa brasileira. Nesse sentido, o presente artigo fará uma avaliação da atuação dessa política relativamente à questão nuclear iraniana. De forma breve, essa questão relaciona-se, de um lado, ao Irã, que pleiteia seu direito de enriquecimento de urânio para fins pacíficos e, de outro, a países e a organismos internacionais, como os P5+1 (as cinco potências com assento permanente no Conselho de Segurança das Nações Unidas - Estados Unidos, China, Reino Unido, França, Rússia - e a Alemanha) e as

\footnotetext{
1 Mestranda do Programa de Pós Graduação em Ciência Política pela Universidade Federal do Paraná, Curitiba-PR, Brasil.

Conjuntura Global, Vol.3, n. 4, out./dez., 2014, p. 194-200. 
Nações Unidas, para os quais o Irã estaria apresentando pouca confiabilidade relativamente ao caráter pacífico de suas atividades nucleares (ONU, 2010).

Nesse contexto, o artigo fará a comparação de dois momentos da política externa brasileira, a saber, o contexto da Declaração de Teerã, de 2010, assinada por Brasil, Turquia e Irã (MRE 2010), e da assinatura do Acordo de Genebra com o Irã, de 2013, mediado pelos P5+1 (EEAS 2013). Essa aproximação analítica permitirá não apenas a discussão sobre os fatores que motivaram o Brasil a atuar de forma protagonista no primeiro contexto, mas também a avaliação das posições brasileiras frente ao novo cenário trazido em 2013, no qual as seis potências internacionais e o Irã pactuaram um Plano Conjunto de Ação que, muito embora não tenha tido a participação direta do Brasil, ocorreu no contexto de um processo mais amplo de busca do diálogo com o Irã e do qual o Brasil tomou parte, com vistas à solução pacífica da controvérsia internacional, a ser discutido no presente artigo.

\section{A Política Externa Brasileira e a Declaração de Teerã de 2010}

Ainda que tenha sido alvo de críticas por parte de setores da mídia nacional (BONFIM 2014), o Brasil logrou, ao lado da Turquia, mediar as negociações com o Irã que culminaram com a assinatura da Declaração de Teerã, em 2010. Para compreender esse fenômeno, é necessário analisá-lo tanto do ponto de vista das implicações internacionais de tal acordo, quanto das motivações internas do Brasil que ensejaram sua participação nesse processo.

Do ponto de vista internacional, diversos motivos reforçam a relevância da questão nuclear iraniana. Em primeiro lugar, o Irã ratificou o Tratado de Não Proliferação (TNP), tratado internacional de 1968 sobre o desarmamento e a não proliferação de armas nucleares que permite o enriquecimento de urânio para fins pacíficos. Não obstante a adesão iraniana ao tratado, desde 2003 a Agência Internacional de Energia Atômica (AIEA) forneceu indícios à comunidade internacional de que o Irã não estaria cumprindo o Acordo de Salvaguardas, que estabelece a necessidade de repassar informações relativas ao recebimento, processamento e armazenamento de materiais nucleares (IAEA, 2003). Nesse sentido, Fonseca (2012, p. 89) evidenciou que algumas posturas iranianas relativamente à AIEA não contribuíam para o aumento de 
confiança com a comunidade internacional. Um exemplo de falta de cooperação ocorreu em 2009, quando um relatório da AIEA reportou a construção de uma nova planta de enriquecimento piloto no Irã, na cidade Qom, sem que o país tivesse avisado previamente a AIEA (AIEA, 2009; DALALIBERA, 2012, p. 41).

Esse fato promoveu grande agitação no cenário internacional, pois, se por um lado reclamou-se a violação ao TNP, por outro o Irã tem, conforme o TNP, direito ao enriquecimento de urânio para fins pacíficos. 0 contexto geopolítico no qual se inseria essa discussão não era menos problemático, haja vista que, em 1998, dois dos vizinhos do Irã, o Paquistão e a Índia, realizaram testes nucleares (PATTI, 2010, p. 181).

Dessa forma, em 2009, a AIEA e os P5+1 firmaram um compromisso com o Irã que previa que o Irã entregasse $1200 \mathrm{Kg}$ de urânio sem enriquecimento e, em troca, recebesse urânio fracamente enriquecido (3,5\%) para fins medicinais. Após ter inicialmente aceitado o acordo, o Irã recusou-se a implementá-lo devido: (1) à falta de garantias da entrega do material enriquecido, e (2) à oposição ao acordo por parte dos setores conservadores do regime (AIEA, 2009; PATTI, 2010, p. 189). Dado esse cenário conturbado, Brasil e Turquia iniciaram, em 2009, as negociações diplomáticas com o Irã que culminaram com a assinatura da Declaração de Teerã, em 2010.

Muitos questionaram os motivos que levaram o Brasil a participar da elaboração dessa declaração dadas: (1) a distância geográfica do Brasil relativamente ao Irã; e (2) a não aceitação do acordo no contexto das Nações Unidas (ONU 2010). Esses questionamentos ensejam o resgate das motivações do Brasil em ladear a Turquia nessa tarefa. Em primeiro lugar, destacam-se as motivações nacionais descritas no Artigo $4^{\circ}$ da Constituição de 1988 (CF), segundo o qual o Brasil se rege, em suas relações internacionais, pela: (i) autodeterminação dos povos; (ii) não intervenção; (iii) solução pacífica de controvérsias; e (iv) cooperação entre os povos para o progresso da humanidade (CF 1988). A esse conjunto de princípios, acrescente-se o fato de o Brasil adotar, tradicionalmente, uma postura legalista no sentido de buscar o respeito aos acordos internacionais e ao direito internacional público (CERVO, 2008). Esses princípios são refletidos na postura do Brasil na questão nuclear iraniana, na medida em que o Brasil tanto enfatiza o respeito aos tratados internacionais, quanto defende que as negociações com o Irã devem ser feitas de forma pacífica, respeitando os direitos de autodeterminação e de não ingerência do Irã. Dessa forma, os princípios que regem as 
relações internacionais do Brasil permitem a ampliação de seu prestígio na cena internacional, na medida em que oferecem ao Brasil tanto a imagem de país cumpridor de contratos, quanto a ampliação das parcerias feitas sob os auspícios da cooperação internacional preconizada na Carta Magna.

Esse marco teórico oferece subsídios à compreensão da atuação protagonista do Brasil no contexto da Declaração de Teerã, na qual o Brasil buscou tanto a solução pacífica da controvérsia quanto uma nova oportunidade de atuação na esfera internacional como país mediador (PATTI, 2010). Esse papel é relevante na seara internacional não apenas por permitir a ultrapassagem de barreiras geográficas, mas também por alçar o Brasil a contribuições que constituiriam um desafio à distribuição tradicional de poder na esfera internacional (CRUZ, 2014). Essa abordagem permite extrapolar a atuação protagonista do Brasil no contexto da Declaração de Teerã e compreendê-la no contexto da estratégia de longo prazo da política externa brasileira, na qual o crescente protagonismo do país na cena internacional e a busca pela reforma de organismos internacionais, como a Organização das Nações Unidas, são complementares e se reforçam mutuamente (VIGEVANI e CEPALUNI, 2007).

No contexto da Declaração de Teerã, também é relevante abordar as motivações para a aproximação do Brasil com a Turquia. Se por um lado, a Turquia, da mesma forma que o Brasil, é percebida como ator de crescente relevância no cenário internacional (SPOHR, 2014, p. 3), por outro ela tem motivações adicionais para desejar esse protagonismo em suas relações externas, como o fato de buscar fazer parte da União Europeia (EURACTIV, 2012), o que poderia ser favorecido com a resolução da questão nuclear do Irã, país que faz fronteira com a Turquia.

Essas motivações criaram um terreno propício à participação ativa da Turquia e do Brasil na elaboração da Declaração de Teerã de 2010, que, de forma semelhante à tentativa de acordo realizada em 2009 com os P5+1 e com a AIEA, previa: (i) a troca de combustível nuclear como ponto de partida para a cooperação, com o depósito pelo Irã de $1200 \mathrm{Kg}$ de urânio levemente enriquecido na Turquia; e (ii) em troca, o Grupo de Viena, formado por Estados Unidos, Rússia e França, entregaria 120 Kg de combustível destinado ao Reator de Pesquisas de Teerã dentro de um ano (MRE, 2010).

Apesar de Brasil e Turquia terem sido bem sucedidos na elaboração da Declaração de Teerã, que foi assinada por esses países e pelo Irã em 17 de Maio de 2010, conjuntura Gıodal, vol.s, n. 4, out./ aez., LUı4, p. 1Y4-८UU. 
o Conselho de Segurança das Nações Unidas autorizou, em 9 junho de 2010, por meio da Resolução 1929 (ONU, 2010), sanções adicionais ao Irã. Essa resolução teve 12 votos favoráveis, uma abstenção e dois votos contrários, do Brasil e da Turquia, que, na época, eram membros rotativos do Conselho de Segurança. Na justificativa do voto, Brasil e Turquia alegaram que as sanções iam na contramão da solução negociada por meio da Declaração de Teerã de 17 de Maio de 2010, a qual ofereceria uma nova oportunidade para a diplomacia naquele contexto. 0 Irã também manifestou seu descontentamento, reafirmando seu direito ao uso pacífico da energia nuclear (ONU, 2010). Não obstante as congratulações aos esforços diplomáticos da Turquia e do Brasil, os membros do Conselho e os P5+1 ressaltaram, nesse contexto, que a Declaração de Teerã não apenas:

(...) não lidou com questões centrais como o cumprimento dos acordos com a Agência Internacional de Energia Atômica (AIEA), o enriquecimento de urânio em desafio ao Conselho e a revelação de uma instalação em Qom não declarada previamente pelo Irã (ONU, 2010).

\section{A Política Externa Brasileira e a Declaração de Genebra de 2013}

No segundo momento da análise - o contexto da Declaração de Genebra de 2013 o Brasil não assumiu o mesmo protagonismo de 2010. Essa Declaração foi elaborada pelos P5+1 e previa que o Irã: (i) autorizaria o acesso de inspetores nucleares ao país e (ii) suspenderia parte de seu programa de enriquecimento de urânio (EEAS 2013). 0 acordo também previa o alívio progressivo das sanções econômicas ao país que foram impostas tanto por organismos multilaterais, quanto por países específicos.

Nesse contexto, o Brasil, por meio de Nota de Imprensa divulgada em 24 de Novembro de 2013 (MRE 2013), afirmou sua satisfação frente ao acordo obtido, enfatizando sua crença na solução negociada como única forma de encaminhamento da questão. Dessa forma, não obstante o afastamento do Brasil da negociação direta do acordo, pode-se afirmar que o Brasil evidenciou sua postura propositiva e cooperativa na cena internacional, tanto em 2010 quanto em 2013, quando o Brasil apoiou o esforço pela negociação pacífica para a questão iraniana.

Ainda que a declaração de Teerã de 2010 não tenha sido operacionalizada, ela simboliza a importância da diplomacia para a resolução de conflitos internacionais, uma vez que fez parte dos esforços de negociação que culminaram com a Declaração de Genebra de 2013. Assim, a falta de implementação da Declaração de Teerã de 2010 não 
invalidou o esforço diplomático do Brasil e da Turquia; ao contrário, constituiu um exemplo de que a manutenção do diálogo, da cooperação e da busca pela solução pacífica são fundamentais para o direcionamento dos contenciosos internacionais, princípios que o Brasil perpetua em sua política externa e que constituem paradigmas a serem buscados pela comunidade internacional, como de fato o foram com a Declaração de Genebra de 2013.

A despeito dos obstáculos encontrados por essa Declaração, cujo prazo de conclusão foi ampliado diversas vezes e que atualmente tem vigência até junho de 2015, tanto Irã quanto as demais potências internacionais envolvidas nas negociações têm grande interesse em chegar a um acordo. De um lado, o Irã já investiu muito em suas usinas nucleares para abrir mão de suas instalações nucleares em troca do alívio das sanções econômicas, de outro, as potências nucleares temem que um retrocesso nas negociações implique a escalada dos investimentos nucleares feitos pelo Irã (ECONOMIST, 2014).

Nesse contexto, o apoio oferecido pela diplomacia brasileira em 2013 simboliza que, a despeito das dificuldades das negociações, o Brasil deseja que prevaleça a mensagem trazida no bojo da Declaração de Teerã, qual seja, a de que a solução pacífica das controvérsias e o respeito aos contratos internacionais são o melhor caminho para a solução desse contencioso internacional de tamanho relevo para as relações internacionais contemporâneas. Em outras palavras: mesmo que a Declaração de Teerã não tenha sido completamente exitosa, os princípios nela contidos e enfatizados pelo Brasil são valiosos para a compreensão e solução da questão iraniana.

\section{REFERÊNCIAS BIBLIOGRÁFICAS}

BONFIM, Ivan. Imagens diplomáticas: uma análise da cobertura foto-jornalística das negociações Brasil-Irã-Turquia no portal VEJA.com à luz da diplomacia midiática. Comun. \& Inf., Goiânia, GO, v. 17, n. 1, p. 63-79, jul./dez. 2014

CERVO, Amado Luiz. Inserção Internacional: Formação dos conceitos brasileiros. São Paulo: Saraiva. 2008.

CONSTITUIÇÃO da República Federativa do Brasil. 1988 (CF 1988)

CRUZ, Jose Humberto de. A questão do poder nacional e o debate sobre a política externa (http://politicaexterna.com.br/2489/questao-poder-nacional-e-o-debatesobre-politica-externa/) [12 de Dezembro de 2014]

Conjuntura Global, Vol.3, n. 4, out./dez., 2014, p. 194-200. 
THE ECONOMIST 2014 Nuclear Talks with Iran (http://www.economist.com/blogs/economist-explains/2014/05/economist-explains5) [12 de Dezembro de 2014]

EEAS 2013 (http://eeas.europa.eu/statements/docs/2013/131124_03_en.pdf) [12 de Dezembro de 2014]

EURACTIV (2012). EU and Turkey relations (http://www.euractiv.com/enlargement/eu-turkey-relations/article-129678) [12 de Dezembro de 2014]

FONSECA, Leandro Dalalibera. A AIEA - Agência Internacional de Energia Atômica e a Efetividade de suas medidas no cumprimento dos dispositivos do tratado de não proliferação nuclear: estudo de casp do Programa Nuclear Iraniano. Dissertação de Mestrado. Curso de Pós-graduação em Ciência Política. Universidade Federal do Paraná. Curitiba, 27 de Junho de 2012.

IAEA, 2003 International Atomic Energy (http://www.iaea.org/Publications/Documents/Board/2003/gov2003-40.pdf) [02 de Dezembro de 2014]

MRE 2010 Ministério das Relações Exteriores do Brasil. (http://www.itamaraty.gov.br/sala-de-imprensa/notas-a-imprensa/declaracaoconjunta-de-ira-turquia-e-brasil-17-de-maio-de-2010) [02 de Dezembro de 2014]

MRE 2013 Ministério das Relações Exteriores do Brasil. (http://www.itamaraty.gov.br/sala-de-imprensa/notas-a-imprensa/entendimentoentre-p5-1-e-ira-sobre-o-programa-nuclear-iraniano) [02 de Dezembro de 2014]

ONU 2010 (http://www.un.org/News/Press/docs/2010/sc9948.doc.htm). Acesso em: 04 de Outubro de 2010 [02 de Dezembro de 2014]

PATTI, Carlo. O Brasil e as questões nucleares nos anos do governo de Luís Inácio Lula da Silva (2003-2010) Rev. Bras. Polít. Int. 53 (2): 178-197 [2010]

PECEQUIL0, Cristina Soreanu. A Política Externa do Brasil no Século XXI: Os Exiso Combinados de Cooperação Horizontal e Vertical. Revista Brasileira de Política Internacional. 51 (2): 136-153, 2008.

SPOHR, Alexandre Piffero As políticas externas brasileira e turca no Século XXI: Uma análise. UFRGS 2o Seminário Nacional de Pós Graduação Associação Brasileira de Relações Internacionais - ABRI 28 e 29 de agosto de 2014, João Pessoa - PB

VIGEVANI, Tullo e CEPALUNI, Gabriel. A Política Externa de Lula da Silva: a estratégia da autonomia pela diversificação. Contexto Internacional, Volume 29, No. 2, JulhoDezembro 2007. (http://www.scielo.br/scielo.php?script=sci_arttext\&pid=S010285292007000200002). [02 de Dezembro de 2014] 